Revisão

\title{
Matriz Extracelular e Leucemia
}

\author{
Adriana R. dos Anjos ${ }^{1}$ \\ Márcio Alvares-Silva ${ }^{2}$ \\ Primavera Borelli ${ }^{1}$
}

\begin{abstract}
A hematopoese é um sistema altamente organizado responsável pela produção das células sanguíneas. O controle da proliferação, diferen ciação e maturação destas células éfei to a través de uma complexa interação molecular das células com o microambiente da medula óssea. Este microambiente complexo produz glicoproteínas solúveis genericamente chamadas de citocinas, que controlam a mitose e a diferenciação das células hematopoéticas.

Nos processos neoplásicos, especialmente nos malignos, ocorrem alterações moleculares induzindo nas células um novo comportamento biológico podendo, inclusive, alterar seus mecanismos de adesão. A interação de células leucêmicas com moléculas da matriz extracelular da medula óssea, pode ser um dos mecanismos utilizados por essas células para chegar ao sangue periférico. Particularmente, precursores celulares, matriz extracelular e interações com células en doteliais determinam a manuten ção ou liberação das células hematopoéticas do microambien te da medula óssea para o sangue periférico. Assim, mudançasna afinidade ou na quantidade de moléculas de adesão pelas células do estroma ou pelos precursores das células sanguíneas, afetarão a adesão celular.

Vários trabalhos têm sido realizados na tentativa de se entender melhor a interação existente entre os precursores hematopoéticos e 0 microambiente indutivo formado pelo estroma medular.

Rev.bras.hematol.hemoter., 2000, 22(3): 414-402
\end{abstract}

Palavras-chave: Leucemia, medula óssea

\section{Introdução}

A hematopoese é um sistema altamente organizado responsável pela produção das células sanguíneas. 0 controle da proliferação, diferenciação e maturação destas células é feito através de uma complexa interação molecular das células com o microambiente da medula óssea (1). Em indivíduos adultos, a hematopoese se compartimentaliza na medula óssea de ossos chatos gerando eritrócitos e leucócitos. Em termos quantitativos a hematopoese apresenta uma produção celular alta, em torno de $10^{12}$ de células sanguíneas/dia/Kg, em adultos. Esta produção é rigidamente controlada por um microambiente indutivo na medula óssea composto por células e por proteínas de matriz extracelular que formam o estroma medular (2).

A medula óssea contém um estroma complexo, consistindo de uma rede de tecido conjuntivo e uma variedade de tipos celulares, incluindo fibroblastos, macrófagos, adipócitos-

1 - Departamento de Análises Clínicas e Toxicológicas, Laboratório de Hematologia Experimental, Faculdade de Ciências Farmacêuticas, USP, Brasil

2 - Departamento de Biologia Celular, Embriologia e Genética, CCB, UFSC, Brasil

Correspondência para: Primavera Borelli

Laboratório de Hematologia, Departamento de Análises Clínicas da Faculdade de Ciências Farmacêuticas da USP Av. Lineu Prestes, 580, Bloco 17, CEP 05508-900, São Paulo, SP, Brasil 
like, células musculares lisas, células reticulares e endoteliais. Os adipócitos medulares aparentemente possuem a função mecânica de controlar o volume hematopoético, que por sua vez controla o aumento de inclusões gordurosas na medula, uma vez que a aceleração da hematopoese está associada com a perda de vacúolos de gordura aumentando os espaços para o crescimento das células hematopoéticas (3).

Macrófagos e osteoclastos derivam-se de células precursoras hematopoéticas, possuindo também importância no microambiente hematopoético. Os macrófagos são importantes na fagocitose dos elementos da eritropoese inefetiva, na remoção do núcleo liberado pelos eritroblastos, pelo fornecimento de ferro para os eritroblastos e talvez possam produzir in situ fatores de crescimento e, ou citocinas regulatórias (4). Todas estas células secretam e são envolvidas por uma complexa matriz extracelular contendo fibronectina, laminina, colágeno tipos III e IV, glicosaminoglicanos como o heparan sulfato e condroitin sulfato, ácido hialurônico, e uma variedade de outras moléculas (5). Este microambiente complexo produz glicoproteínas solúveis genericamente chamadas de citocinas, que controlam a mitose e a diferenciação das células hematopoéticas (6).

Em indivíduos normais todo o programa de proliferação e diferenciação das células hematopoéticas é estritamente controlado pelo microambiente indutivo (7). Já foi demonstrado que a proliferação de células neoplásicas é dependente da produção autócrina de citocinas $(8,9)$ e da interação com componentes da matriz extracelular (MEC) $(10,11)$.

Nos processos neoplásicos, especialmente nos malignos, ocorrem alterações moleculares induzindo as células a um novo comportamento biológico podendo, inclusive, alterar seus mecanismos de adesão. A hipótese de que as moléculas de adesão possuam papel importante na regulação da hematopoese normal é sugerida pelo aumento do número destas moléculas presentes na matriz extracelular e na superfície das células progenitoras, além de seus diferentes padrões de expressão durante os estágios de diferenciação das linhagens celulares.
Particularmente, precursores celulares, matriz extracelular e interações com células endoteliais determinam a manutenção ou liberação das células hematopoéticas do microambiente da medula óssea para o sangue periférico. Consequentemente, mudanças na afinidade ou quantidade de moléculas de adesão expressas no estroma da medula óssea ou nos precursores das células do sangue durante o desenvolvimento normal ou durante um processo neoplásico, afetarão a adesão celular. Assim, as moléculas de adesão podem ser um dos moduladores que alteram o comportamento biológico das células hematopoéticas normais ou leucêmicas, primeiramente em termos de migração e adesão, muito embora participem também de muitas outras funções celulares como citotoxicidade e apresentação de antígenos (12).

A alteração nos processos de regulação da hematopoese no aspecto celular pode ser vista de uma maneira sintética como sendo a manifestação de alterações no controle dos três tipos de respostas: proliferação, diferenciação e maturação. As leucemias são neoplasias malignas, de natureza clonal, das células primordiais hematopoéticas, caracterizadas pela substituição difusa da medula óssea por células neoplásicas. As células leucêmicas, na maioria das vezes, podem chegar ao sangue periférico e ainda infiltrar no fígado, linfonodos e outros tecidos do corpo (13).

\section{Leucemias e Estroma Medular}

As leucemias são classificadas de acordo com o tipo celular envolvido e o grau de maturação das células. As leucemias agudas (LA) caracterizam-se pela proliferação clonal acompanhada de bloqueio maturativo (anaplasia) variável, o que possibilita a existência de diferentes subtipos de leucemias. Já nas leucemias crônicas (LC), a proliferação clonal não está associada inicialmente a um bloqueio maturativo. Assim, a população celular diferencia-se e amadurece, embora haja graus variáveis de displasia, o que compromete funcionalmente a população celular afetada. 
A leucemia mielocítica crônica (LMC) é uma neoplasia maligna clonal que afeta a célula primitiva. Alterações na adesão destas células à matriz extracelular da medula óssea têm sido propostas como uma das causas que justificariam a presença de células blásticas leucêmicas no sangue periférico. Contudo, pesquisas laboratoriais demonstraram que a expressão de uma proteína quimérica $B C R / A B L$ por células transfectadas, podem sob certas condições, aumentar a adesão à fibronectina via aumento da expressão de integrinas (14). Cacciola et al. (1997) (15) estudando as integrinas da subfamília ß1 na adesão célulacélula e célula-matriz extracelular, demonstraram que mudanças na expressão desta molécula ou de sua função sinalizadora, refletem em distúrbios no microambiente da medula óssea. Assim, as moléculas de adesão parecem ter um papel importante na regulação da hematopoese normal.

A hematopoese anormal na LMC relacionase, pelo menos em parte, às alterações das próprias células hematopoéticas, levando à interações anormais entre elas e o estroma medular (16). Células progenitoras consideradas normais aderem com intensidade ao estroma medular e permanecem normalmente quiescentes quando em contato com este estroma $(17,18)$. Por outro lado, as células progenitoras da LMC apresentam reduzida adesão ao estroma formado por células normais $(19,20)$ e continuam proliferando mesmo quando em contato com este estroma (21). Isto pode acontecer, em parte, devido as funções anormais dos receptores de adesão presentes nestes progenitores na $\operatorname{LMC}(20,22)$.

Os macrófagos teciduais são derivados dos monócitos originados dos progenitores hematopoéticos presentes na medula óssea. Os monócitos de pacientes com LMC derivam do clone maligno BCR/ABL positivo; assim uma proporção destes macrófagos do estroma, na LMC, pode ser de origem maligna (16). Esses autores formulam a hipótese que macrófagos derivados do clone $B C R / A B L$ positivo apresentavam anormalidades em suas funções no estroma da medula óssea, uma vez que, o estroma medular na LMC apresentava uma capacidade reduzida em suportar o crescimento de células progenitoras normais. Células de origem maligna, identificadas como macrófagos do estroma medular, estavam presentes em pacientes com LMC e pareceram ser as responsáveis pelas funções anormais deste estroma. Por outro lado, o crescimento das células progenitoras obtidas da medula óssea de pacientes com LMC quando em contato com o estroma também obtido de medula óssea de pacientes com LMC, não foi impedido de proliferar. Estes resultados sugerem que anormalidades nas funções do microambiente medular podem contribuir para a expansão seletiva dos progenitores hematopoéticos malignos nos pacientes com LMC (16).

Ensaios in vitro realizados com células obtidas da medula óssea de pacientes com LMA, cultivadas sem fatores de crescimento, entraram rapidamente em apoptose (23). Contudo, 0 contato com o estroma medular e seus fatores de crescimento diminuíram o número de células em apoptose (23), modularam a diferenciação (24) e aumentaram a proliferação (25). Citocinas, como fator estimulador de colônias granulocíticas (G-CSF), fator estimulador de colônias granulocíticas e monocíticas (GM-CSF), fator estimulador de colônias monocíticas (MCSF), interleucina-3 (IL-3) e IL-6 são capazes de estimular 0 crescimento dos blastos presentes em pacientes com LMA $(8,26,27)$.

Na medula óssea de pacientes com LMA, o número de fibroblastos e células endoteliais está aumentado, enquanto o número de macrófagos não difere quando comparado com indivíduos normais (28). Estudos realizados por Denkers et al. (1992) (29), demonstraram a diferença no desenvolvimento e na composição celular de culturas de longa duração obtidas de indivíduos normais e de pacientes com LMA. Durante seis semanas as culturas de longa duração com células obtidas da medula óssea de indivíduos não leucêmicos, apresentaram aumento do número de fibroblastos e diminuição do número de macrófagos. Este estroma obtido da medula óssea de indivíduos normais mostrou um bom desenvolvimento com auto-renovação das células que o constituíam. 
Por outro lado, o estroma obtido da medula óssea de pacientes leucêmicos não apresentou auto renovação, muito embora o número de fibroblastos se encontrasse aumentado e o número de macrófagos diminuído, durante as seis semanas de cultura, resultado este parecido ao obtido com o estroma "normal". Aparentemente, as células leucêmicas modificariam a composição do estroma "leucêmico". Pacientes com prolongado tempo de remissão da doença, após tratamento quimioterápico, podem permanecer com número de células hemato poéticas alterado por muitos anos. Ensaios com cultura de longa duração das células desses pacientes não apresentaram confluência das células do estroma medular (30).

$\mathrm{Na}$ medula óssea de pacientes com LMC a camada aderente formada nas culturas de longa duração possui a mesma constituição do estroma obtido de indivíduos normais (16). Contudo, funcionalmente, este estroma não proporciona boas condições para o crescimento de células hematopoéticas normais, podendo relacionar-se à anormalidades dos macrófagos constituintes desse estroma $(16,31)$. Uma vez que os pacientes com LMC entram na fase blástica, o estroma também se modifica, tornando-se semelhante ao estroma da medula óssea de pacientes com LMA, aumentando a produção de citocinas como IL-1ß, IL-6, GM-CSF (32).

Quanto às moléculas de adesão, Denkers et al. (1992) (29), demonstraram diferenças na expressão destas moléculas nas culturas de longa duração empregando células obtidas da medula óssea de indivíduos normais e células obtidas da medula óssea de indivíduos leucêmicos. O utros autores não detectaram a expressão dos receptores de superfície VLA-1 e VLA-6 nos macrófagos presentes no estroma (33). A menor expressão das moléculas de adesão pelas células do estroma medular poderia ser um dos fatores responsáveis pela liberação das células leucêmicas da medula óssea para a corrente sanguínea, contudo, outros fatores como a constituição do estroma, também podem modificar a migração celular (34).

As interações entre células precursoras, matriz extracelular e células endoteliais determinam a permanência ou liberação das células hemato poéticas do microambiente da medula óssea para a circulação sanguínea. Consequentemente, mudanças na afinidade ou na quantidade das moléculas de adesão no estroma medular ou nas células precursoras durante os processos malignos, afetam a adesão (35).

\section{Matriz Extracelular e Moléculas de Adesão}

A matriz extracelular (MEC) pode ser definida como a organização supramolecular de diversas proteínas estruturais e polissacarídeos nos tecidos conjuntivos, compreendendo colágeno, glicoproteínas não colagenosas, proteoglicanos, glicosaminoglicanos, elastina e ácido hialurônico (36), que preenchem os espaços extracelulares. Já foi demonstrado que os componentes da MEC podem controlar eventos como adesão celular, migração e proliferação de diferentes células. As células depositam no meio extracelular componentes como colágeno (37), fibronectina (FN), laminina (38), trombospondina (39), hemonectina (40), proteoglicanos e ácido hialurônico $(41,42)$, produzidos principalmente pelos fibroblastos e distribuídos em uma rede organizada em íntima associação com a superfície da célula que a produziu. Estes componentes geram, portanto, a MEC do estroma medular.

Devido à complexidade do estroma medular, uma grande variedade de componentes desse estroma pode estar envolvida na adesão de células hematopoéticas normais ou leucêmicas.

Dentre as várias substâncias que fazem parte da matriz extracelular podemos destacar a laminina, fibronectina e o colágeno tipo IV, pela grande importância nos processos de adesão e migração de vários tipos celulares, inclusive as células hematopoéticas.

Os processos de adesão também envolvem a participação de receptores específicos para células hematopoéticas. Muitas proteínas de superfície com funções adesivas podem ser identificadas nas células hematopoéticas, como as integrinas, selectinas, superfamília das imunoglobulinas e receptores de citocinas (5). 
Muitas moléculas de adesão com função de mediar as interações célula-célula ou célulamatriz, têm sido identificadas em modelos experimentais utilizando medula óssea $(43,44)$. A superfamília das integrinas desempenham papel importante no desenvolvimento da resposta imune, na agregação plaquetária e na reparação tecidual $(45,46)$, além do seu papel na linfomielopoese $(33,47,48)$. A subfamília ß1 (VLA) é constituída por receptores dos componentes da matriz extracelular, sendo que sua expressão acontece tanto em células hematopoéticas como em células não hematopoéticas $(45,49)$. Os sete componentes da subfamília VLA diferem pela associação de diferentes cadeias a com a mesma cadeia $ß 1$ $(43,49,50)$. A expressão das integrinas VLA nas células hemato poéticas inclui: VLA-1, VLA2 e VLA-6 (CD49 a, b, e) presentes nas células $\mathrm{T}(50,51)$ e VLA-2 e VLA-6 presentes nas plaquetas $(33,51)$. As integrinas VLA-4 (CD 49d) e VLA-5 (CD49e) são as de maior expressão nas células hematopoéticas $(33,43,48,51,52)$.

Liesveld et al. (1989, 1991) $(53,54)$ investigaram a interação in vitro dos progenitores mielóides com o estroma da medula óssea, concluindo que um subgrupo de células da medula óssea humana apresentava antígenos CD34 ligados à camada de estroma medular, e em menor extensão, à matriz extracelular da medula, à fibronectina e à laminina. Em 1993 (55) os mesmos autores demonstraram que progenitores da linhagem mielóide, incluindo as células normais CD34 positivas e células da LMA, apresentavam um padrão similar de integrinas VLA. Usando uma linhagem leucêmica de células monocíticas - U937, Pucillo et al. (1993) (11) demonstraram que o tratamento in vitro com TPA (12-0-tetradecainoil phorbol-13-acetato), aumentou a expressão das integrinas a5, a3, e a taxa de adesão desta linhagem às moléculas de matriz extracelular.

\section{Matriz Extracelular e Proteoglicanos}

Os Proteoglicanos (PGs) são constituídos por proteínas ligadas covalentemente a polissacarídeos sulfatados: os glicosaminoglicanos (GAGs), como condroitin (CS) e, ou heparan sulfato (HS) (56), podendo ser encontrados na superfície celular ou na matriz extracelular. Os
PGs são moléculas importantes na constituição do microambiente medular tanto em termos quantitativos (37) quanto sob o ponto de vista funcional (57), existindo evidências de que são importantes nos processos de migração.

Já foi demonstrado que proteoglicanos da superfície celular participam tanto do reconhecimento quanto da ligação às citocinas (58). A síntese dos proteoglicanos pode estar sob o controle de citocinas específicas, que por sua vez, podem aumentar a expressão dos proteoglicanos na superfície celular, promovendo maior adesão das células neoplásicas aos componentes da matriz extracelular, tal como a fibronectina (59). O CD44, por exemplo, é um receptor produzido pelas células tumorais que contém condroitin sulfato em sua estrutura molecular, podendo se ligar à fibronectina, colágeno tipo I e à laminina (60). Esta isoforma de CD44 pode contribuir em eventos como migração e proliferação celular (61), adesão celular, indução da diferenciação hematopoética e interações com sinais de ativação celular (60). O CD44 pode ser considerado um dos principais receptores de superfície celular para o ácido hialurônico, um glicosaminoglicano componente da matriz extracelular (62).

Os glicosaminoglicanos possuem diferentes estruturas e propriedades fisicoquímicas que podem influenciar a proliferação, adesão e diferenciação das linhagens celulares. Efeitos específicos dos glicosaminoglicanos sobre células leucêmicas poderiam ajudar na compreensão da regulação da proliferação e diferenciação das células hematopoéticas. Volpi et al. (1994) (63), avaliaram a participação de diferentes glicosaminoglicanos na proliferação e diferenciação da linhagem U937 (linfoma, monócito-like) e encontraram que heparina e seus derivados foram capazes de inibir a proliferação celular. Ainda segundo esses autores o heparan sulfato não produziu modificações, enquanto que o condroitin sulfato e dermatan sulfato estimularam significativamente o crescimento celular.

A interação entre as células normais e 0 endotélio é regulada por diversas glicoproteínas de membrana como as integrinas e proteoglicanos $(46,64,65)$. Entretanto, poucos trabalhos na literatura avaliaram 0 papel de PGs na membrana de células 
leucêmicas. Ridley et al. (1993) (66) demonstraram que as neoplasias oriundas de células $B$, como o mieloma múltiplo, expressavam grandes quantidades de PGs na sua superfície capazes de interagir com colágeno, favorecendo a sua disseminação em diversos tecidos como ossos, rins, linfonodos, baço e fígado. Yahlom, et al. (1988) (67) estudaram a expressão de heparanase por HL60 e U937. Esta enzima degrada heparan sulfato na matriz extracelular subendotelial e parece estar presente em linfócitos e macrófagos ativados e em células tumorais com alta atividade metastática, facilitando assim a invasão dos vasos sanguíneos.

\section{Leukemia and extracelular matrix}

Adriana R. dos Anjos, Márcio Alvares-Silva, Primavera Borelli1

\section{Abstract}

Hematopoesis is an organize system that is responsible for blood cells production. The proliferation, differentiation and maturation control of this cells is achieved by interaction between cells and medular microenvironment. This microenvironment produce glicoproteins called cytokines, that control proliferation of hematopoietic cells.

In neoplasic processes, several molecular alterations occur, it induce a new biological behaviour by cells, like become altered its adhesion. The interaction of leukemic cells with the extracellular matrix (ECM) of bone marrow can be considered one of the mechanisms used by these cells to reach the peripheric blood. Privately, precursor cells, ECM and endthelial cells control the main tennance or release of this hematopoietic cells to peripheric blood. In this way, changes in affinity or in molecular amount by stroma cells or by precursors of blood cells will afect cellular adhesion.

Thefore several works have been realized to understand very much about the interaction between hematopoietic progenitors cells and the microenvironment constituted by medular stroma. Rev.bras.hematol.hemoter.,2000,22(3):404-412

Key words: Leukemia, bone marrow

\section{Referências Bibliográficas}

1. Sachs, L. The adventures of a biologist: prenatal diagnosis, hematopoiesis, leukemia, carcinogenisis and tumor supression. Adv. Cancer Res. 1995; 66: 1-40.

2. Dexter, T.M., Testa, N.G. In vitro methodos in haemopoiesis and lymphopoiesis. J.Immunol. Methods 1980; 38: 177-190.

3. Tavassoli, M. Marrow adipose cells and hemapoiesis: an interpretative review. Exp. Hematol. 1984; 12:139-146.

4. Fernández, M., Minguell, J.J. The role of collagen in hematopoiesis. Braz. J. Med. Biol. Res. 1996; 29:1201-1207.

5. Bradstock, K.F., Gottlieb, D.J. Interaction of acute leukemia cells with the bone marrow micrenvironment: implications for control of minimal residual disease. Leuk. Lymphoma Res. 1995; 18:1-16.

6. Holtmann, H., Resch, K. Cytokines. Naturwissenschaften 1995; 82:178-187.

7. Quesenberry, P., Temeles, D., McGrath, H. et. al. Long term marrow cultures: human and murine systems. J. Cell. Biochem. 1991; 45:273-278.

8. Minden, M. Growth factor requirements for normal and leukemic cells. Semin.Hematol. 1995; 32:162-182.

9. Nicolson, G.L. Cancer progression and growth: relationship of paracrine and autocrine growth mechanisms to organ proference of metastasis. Exp. Cell Res. 1993; 204: 171-180.

10. Brach, M.A, Herrmann, F. Hematopoietic growth-factors: interactions and regulation of production. ActaHaematol. 1991; 86:128-137.

11. Pucillo, C.E.M., Colombatti, A., Vitale, M. et al. Interations of promonocytic U937 cells with proteins of the extracellular matrix. Immunology 1993; 80:248-252.

12. Paietta, E. Adhesion molecules in acute myeloid leukemia. Leuk. Res. 1996; 20:795-798.

13. Cotran, R.C., Kumar, V., Robbins, S.L. Doenças dos leucócitos, linfonodos e baço. In: Cotran, R.C., Kumar, V., Robbins, S.L. Patologia estrutural e funcional. 4 ed. Rio de Janeiro: Guanabara Koogan, 1998. P.593-598. 
14. Pasternak, G., Hochhaus, A., Schultheis, B., Hehlmann, R. Chronic myelogenous leukemia: molecular and cellular aspects. J. Cancer Res. Clin. Oncol. 1998; 124:643-660.

15. Cacciola, R.R., Stagno, F., Impera, S. et al. Beta-1-integrin expression in adult acute lymphoblastic leukemia: possible relationship with the stem cell antigen CD34. Acta Haematol. 1997; 97:63-66.

16. Bhatia, R., McGlave, P.B., Dewald G.W., Blazar, B.R., Verfaillie, C.M. Abnormal function of bone marrow microen viron ment in chronic myelogenous leukemia: role of malignant stromal macrophages. Blood 1995; 85: 3636-3645.

17. Cashman, J., Eaves, AC., Eavea, C.J. Regulated proliferation of primitive hematopoietic progenitors in long-term human marrow cultures. Blood 1985; 66:1002-1008.

18. Verfaillie, C., Blakholmer, K., McGlave, P. Purified primitive human hematopoietic progenitors with long term in vitro repopulatting capacity adhere selectively to irradiated bone marrow stroma. J. Exp. Med. 1990; 179:509-515.

19. Gordon, M.Y., Dowding, C.R., Riley, G.P., Goldman, J.M., Greaves, M.F. Altered adhesive interactions with stroma of hematopoietic progenitors cells in chronic myelogenous leukaemia. Nature 1984; 328: 342-350.

20. Verfaillie, C.M., McCarthy, J.B., McGlave, P.B. Mechanismsunderlyingabnormal trafficking of malignant progenitors in chronic myelogen ousleukemia. Decresed adhesion to stroma and fibronectin but increased adhesion to the basement membrane components laminin and collagen type IV. J.

Clin. Invest. 1992; 90: 1232-1241.

21. Eaves, AC., Cashman, J.D., Gaboury, L.A., Kalousek, D.K., Eaves, C.J. Unregulated proliferation of primitive chonic myelogenous leukemia progenitors in the presence of normal marrow adherent cells. Proc. Nat. Acad. 1986; 83: 5306-5310.

22. Bhatia, R., Wayner, E.A., McGlave, P.B., Verfaillie, C.M. Interferon-a restores normal adhesion of chronic myelogenous leukemia hematopoietic progenitors to bonemarrow stroma by correcting impaired ß1 integrin receptor function. J. Clin. Invest 1994; 94: 384-391.
23. Bendall, L.J., Daniel, A., Kortlepel, K., Gottlieb, D.J. Bone marrow adherent layers in hibit apoptosis of acute myeloid leukemia cells. Exp. Hematol. 1994; 22: 1252-1260.

24. Scholzel, C., Lowenberg, B. Stimulation of proliferation and differentiation of acute myeloid leukemia cells on a bone marrow stroma in culture. Exp. Hematol. 1985; 13: 664-669.

25. Shibata, T., Inoue, S., Gohle, N., Karanes, C. Maintenance of myeloid leukemic cellsin the adherent layers of long-term bone marrow cultures. Jpn. J. Clin. Oncol. 1987; 17:3-11.

26. Griffin, J.D., Low enberg, B. Clonogenic cells in acute myeloblastic leukemia. Blood 1986; 68: 1185-1195.

27. Lowenberg, B., Touw, I.P. Hematopoietic growth factors and their receptors in acute leukemia. Blood 1993; 81: 281-292.

28. Dilly, S.A., Jagger, C.J. Bone marrow stromal cell changes in haematological malignancies. J. Clin. Pathol. 1990; 43: 942-946.

29. Denkers, I.A.M., Beelen, R.H.J., Ossenkoppele, G.J. et al. Differences of cellular composition and adhesion molecule expression in "leukemic"as compared with "normal"human long-term bone marrow cultures. Ann. Hematol. 1992; 64: 210-216.

30. Chang, J., Geary, C.G., Testa, N.G. Long-term bone marrow damage after chemotherapy for acute myeloid leukaemia does not improve with time. Br. J. Haematol. 1990; 75: 68-72.

31. Takahashi, M., Keating, A., Singer, J.W. A functional defect in irradiated adherent layers from chronic myelogenous leukemia long-term marrow cultures. Exp. Hematol. 1985; 13: 926-931.

32. Wetzler, M., Kurzrock, R., Lowe, D.G. et al. Alteration in bone marrow adherent layer growth factor expression: a novel mechanism of chronic myelogenous leukemia progression. Blood 1991; 78: 2400-2406.

33. Soligo, D., Schiro, R., Luksch, R. et al. Expression of integrins in human bone marrow. Br. J. Haematol. 1990; 76: 323-332.

34. Weide, M.V.D., Langenhuijsen, M.M.A.C., Huijgens, P.C. et al. Relation between leukaemic cell count and degree of maturation in acutemyeloid leukaemia. Eur. J. Cancer Clin. Oncol. 1987; 23: 1125-1129. 
35. Thomas, X., Anglaret, B. Cell adhesion molecules: expression and function in acute myeloid leukemia. Bull. Cancer 1999; 86: 265-277.

36. Schuppan, D., Ruhl, M. Matrix in signal transduction and growth factor modulation.

Braz. J. Med. Biol. Res. 1994; 27: 2125-2142.

37. Bentley, S.A., Kirby, S.L., Anklesaria, P., Greenberger, J.S. Bone marrow stromal proteoglycan heterogeneity: phenotipic variability between cell lines and the effects of glucocorticoid. J. Cell. Physiol. 1988; 136:182-187.

38. Campbell, A., Wicha, M.S., Long, M. Extracellular matrix promotes the growth and differentiation of murine hematopoietic cells in vitro. J. Clin. Invest. 1985; 75: 2085-2090.

39. Long, M.W., Dixit, V.M. Thrombospondin functions as a cytoadhesion molecule for human hematopoietic progenitor cells. Blood 1990; 75: 2311-2318.

40. Peters, C., O'Shea, K.S., Campbell, A.D., Wicha, M.S., Long, M.W. Fetal expression of hemonectin: na extracellular matrix hematopoietic cytoadhesion molecule. Blood 1990; 75: 357-364.

41. Keating, A., Gordon, M.Y. Hierarchical organization of hematopoietic microenvironments: role of proteoglycans. Leukemia 1988; 2: 766-769.

42. Siczkowski, M., Amos, S.A., Gordon, M.Y. Hyaluronic acid regulates the function and distribution of sulfated glycosaminoglycans in bone marrow stromal cultures. Exp. Hematol. 1993; 21: 126-130.

43. Guan, J.L., Hynes, R. Lymphoid cells recognize na alternatively spliced segment of fibronectin via the integrin receptor a4ß1. Cell 1990; 60: 53-60.

44. Witte, P.L., Robinson, M., Henley, A. et al. Relationships between $B$-lineage lymphocytes and stromal cells in long-term bone marrow cultures. Eur.J. Immunol. 1987; 17:1473-1480.

45. Cassiman, J.J. The involviment of the cell matrix receptors, or VLA integrins, in the morphogenetic behavior of normal and malignant cells isgradually being uncovered.

Cancer Genet. Cytogenet. 1989; 41: 19-25.

46. Hynes, R.O. Integrins: versatility, modulation and signaling in cell adhesion. Cell 1992; 69: 11-25.
47. Kansas, G.S., Muirhead, M.J., Dailey, M. Expression of the CD11/CD18, leukocyte adhesion molecule 1 , and CD44 adhesion molecules during normal myeloid and erythroid differentiation in humans. Blood 1990; 76: 2483-2489.

48. Ryan, D.H., Nuccie, B.L., Abboud, C.N., Winslow, J.M. VLA-4 and CAM-1 mediate adhesion of human $B$ cell precursors to cultured bone marrow adherent cells. J. Clin. Invest. 1991; 88: 995-1002.

49. Humphries, M.J. The molecular basis and specificity of integrin-ligand interactions. J. Cell Sci. 1990; 97: 585-590.

50. Shimizu, Y., Van Seventer, G.A., Horgan, K.J., Shaw, S. Regulated expression and binding of three VLA (ß1) in tegrin receptorson T cells. Nature 1990; 345: 250-255.

51. Long, M.J. Blood cell cytoadhesion molecules. Exp. Hematol. 1992; 20: 288-290.

52. Rosenblatt, M., Vuillet-Gaugier, M.H., Leroy, C., Coulombel, L. Coexpression of two fibronectin receptors, VLA-4 and VLA- 5 by immature human erythroblastic precursor cells. J. Clin. Invest 1991; 87: 6-10.

53. Liesveld, J.L., Abboud, C.N., Duerst, R.E. et al. Characterization of human marrow stromal cells: Role in progenitor cell binding and granulopoiesis. Blood 1989; 73: 1794-1802.

54. Liesveld, J.L., Winslow, J.M., Kempski, M.C. et al. Adhesive interactions of normal and leukemic human $34^{+}$myeloid progenitors: Role of marrow stromal, fibroblast and cytomatrix components. Exp. Hematol. 1991; 19: 63-70.

55. Liesveld, J.L., Winslow, J.M., Frediani, K.E., Ryan, D.H., Abboud, C.N. Expression of integrins and examination of their adhesive function in normal and leukemic hematopoietic cells. Blood 1993; 81: 112-121.

56. Gallagher, J.T. The extended family of proteoglycans: social residents of the pericellular zone. Curr. Opin. Cell Biol. 1989; 1:1201-1218.

57. Klein, G., Conzelmann, S., Beck, S., Timpl, R., Müller, C.A. Perlecan in human bone marrow: a growth-factor-presenting, but anti-adhesive, extracellular matriz component for hematopoietic cells. Matrix Biol. 1995; 14: 457-465. 
58. Conget, P., Minguell, J.J. Modifications in the synthesis of menbrane-associated chondroitin sulfate proteoglycans in hemopoietic progenitor cells are accompanied by alterations in their adhesive properties. J. Cell. Physiol. 1994; 159: 142-150.

59. Conget, P., Minguell, J.J. IL-3 increases surface proteoglycan synthesis in haemopoietic progenitors and their adhesiven ess to the heparin-binding domain of fibronectin. Br. J. Haematol. 1995; 89: 1-7.

60. Lesley, J., Hyman, R., Kincade, P.W. CD44 and its interaction with extracellular matrix.

Adv. Immunol. 1993; 54: 271-335.

61. Alvarez-Silva, M., Trentin, AG. Undersulfation of glycosaminoglycans reduces the proliferation of a leukemia cell line in vitro. Braz. J. Med. Biol. Res. 1996; 29: 1239-1242.

62. Smadja-J offe, F., Legras, S., Girard, N. et al. CD44 and hyaluronan binding by human myeloid cells. Leuk. Lymphoma Res. 1996; 21: 407-420.
63. Volpi, N., Petrini, M., Conte, A. et al. Effects of glycosaminoglycanson U937 leukemia cell proliferation and differentiation: structurefunction relationship. Exp. Cell. Res. 1994; 215: 119-130.

64. Gallagher, J.T., Turnbull, J.E., Lyon, M. Patterns of sulphation in heparan sulphate polymorphism based on a common structural theme. Int J. Biochem. 1993; 24: 553-560.

65. Norris, W.E. Evidence for a second class of membrane glycoprotein involved in cell adhesion. J. Cell Sci. 1989; 93: 631-640.

66. Ridley, R.C., Xiao, H., Hata, H. et al. Expression of syndecan regulates human myeloma plasma cell adhesion to type I collagen. Blood 1993; 81: 767-774.

67. Yahalom, J., Fibach, E., Bar-Tana, R., Fuks, Z., Vlodavsky, I. Differentiating human leukemic cells expressheparanasethat degradesheparan sulfate in subendothelial extracellular matrix. Leuk. Res. 1988; 12: 711-717.

Recebido: $11 / 06 / 2000$

Aceito: $12 / 11 / 2000$ 